This document is the Accepted Manuscript version of a Published Work that appeared in final form in Macromolecules, copyright $\odot 2019$ American Chemical Society after peer review and technical editing by the publisher.

To access the final edited and published work see https://doi.org/10.1021/acs.macromol.9b00469

\title{
Isomorphic polyoxyalkylenes copolyethers obtained by copolymerization of aliphatic diols
}

Andere Basterretxea ${ }^{1,3}$, Elena Gabirondo ${ }^{1}$, Irma Flores ${ }^{1}$, Agustin Etxeberria ${ }^{1}$, Alba Gonzalez ${ }^{1}$, Alejandro J. Müller ${ }^{1,2 *}$, David Mecerreyes ${ }^{1,2}$, Olivier Coulembier ${ }^{3}$, Haritz Sardon ${ }^{1 *}$

${ }^{1}$ POLYMAT and Polymer Science and Technology Department, Faculty of Chemistry, University of the Basque Country UPV/EHU, Paseo Manuel de Lardizabal, 3, 20018 DonostiaSan Sebastián, Spain

${ }^{2}$ Ikerbasque, Basque Foundation for Science, E-48011 Bilbao, Spain

${ }^{3}$ Center of Innovation and Research in Materials and Polymers (CIRMAP), Laboratory of Polymeric and Composite Materials, University of Mons, Place du Parc 23, 7000 Mons, Belgium

KEYWORDS: Aliphatic copolyether, organocatalysis, copolymerization, isomorphism, crystallinity

*Corresponding authors: alejandrojesus.muller@ehu.es, haritz.sardon@ehu.es 


\section{ABSTRACT}

Isomorphism in random copolymers occurs when comonomer units can crystallize within a single crystalline lattice in the entire composition range. This ideal behavior is rare in random copolymers and only a few examples of isomorphism are found in copolyesters and copolycarbonates. In this work, we show a series of polyoxyalkylenes copolyethers obtained by copolymerization of 1,6hexanediol and 1,12-dodecanediol which are able to crystallize in the entire composition range and display an isomorphic behavior. The copolymers were synthesized via a bulk selfcondensation method at high temperature, using a thermally stable Non-Eutectic Mixture Organocatalyst (NEMO) prepared from methanesulfonic acid (MSA) and 1,5,7triazabicyclo[4.4.0]dec-5-ene (TBD). The final molar ratios of the copolyethers were calculated by ${ }^{1} \mathrm{H}$ NMR spectroscopy and the random distribution of the two monomeric units was confirmed by ${ }^{13} \mathrm{C}$ NMR spectroscopy. The effect of the composition of comonomer units on the crystalline structure was investigated by DSC and WAXS. The two comonomeric units along the chain can co-crystallize regardless of the composition, while displaying melting point values that vary linearly in between those of the parent homopolymers $\left(54,9\right.$ and $\left.84,7^{\circ} \mathrm{C}\right)$. The crystalline reflections given by WAXS demonstrated that the two comonomers are miscible in the crystalline state and meet the general criteria to be regarded isomorphic random copolymers. Finally, a random terpolymer was synthetized from 1,6-hexanediol, 1,10-decanediol and 1,12-dodecanediol, which also shows a single melting temperature, thus demonstrating the versatility of the polymerization route employed. 


\section{INTRODUCTION}

Polyethers or polyoxyalkylenes are polymers that contain R-O-R' bonds in the main polymer backbone, where R and R' comprise any alkyl or aryl moieties. ${ }^{1}$ Since their first synthesis by Wurtz in the 1860s, aliphatic polyethers received tremendous attention due to their versatility, thermal and chemical stability, and multiple applications ranging from surfactants, automotive industry, batteries, food and cosmetic industry to nanomedicine. ${ }^{1-4}$ Among the different aliphatic polyethers, polyethyleneglycol (PEO or PEG), polypropyleneglycol (PPG) or polytetramethyleneglycol (PTMG or PTHF) are nowadays the most employed ones, as they can simply be prepared by the ring-opening polymerization (ROP) of the corresponding cyclic ether. ${ }^{5-}$ 7

However, polyethers containing 6 or more methylene units between ether linkages cannot be obtained by ROP because the corresponding cyclic ethers are extremely stable. In these cases, the production of longer methylene unit polyethers can only be carried out using step-growth polymerization methods. In the past, these polyethers were mostly produced by the polycondensation between a nucleophlilic alkoxide on an alkylating reagent (typically a halogenated alkane). ${ }^{8}$ Very recently, more sustainable step-growth polymerization approaches of polyethers have been reported. ${ }^{9-12}$ For instance, Meier et al. prepared polyethers by the catalytic reduction of polyesters. ${ }^{12}$

Our group recently found that medium-to-long chain aliphatic homopolyethers could be easily prepared by the bulk self-condensation of alcohols in the presence of Non-Eutectic Mixture Organocatalyst (NEMO) based on methanesulfonic acid (MSA) and 1,5,7-triazabicyclo[4.4.0]dec-

5-ene (TBD) (3:1). ${ }^{13}$ As a result, highly semicrystalline polyoxyalkylenes with a number of methylene units ranging from 6 to 12 units were obtained. Polyoxyalkylenes homopolymers 
presented semicrystalline behavior showing $T_{m}$ values between 54 and $85{ }^{\circ} \mathrm{C}$ as a function of the number of methylene units along the chain. Furthermore, this method should allow in a very simple way to prepare a series of random copolymers by just choosing the composition of diols in the comonomer initial feed.

Generally speaking there are three different manners in which random copolymers could crystallize depending on the exclusion/inclusion balance or in other words, on the possibility of co-crystallization $^{14}$ : (a) Isomorphism. When comonomeric units can co-crystallize and share a single crystalline unit cell and comonomer exclusion during crystallization never occurs. (b) Total Exclusion of second co-monomer units in the crystals. This case occurs when only the major component of the copolymer is able to crystallize and total comonomer exclusion can occur during random copolymers crystallization. (c) Isodimorphism. An intermediate case is that of isodimorphic crystallization. In these copolymers, there is a balance between exclusion and inclusion that depends on the chemical structure of the comonomeric units. Two crystalline phases can be formed depending on composition and thermal transitions display a pseudo-eutectic point when plotted as a function of composition. Among those crystallization behaviors of random copolymers the unique crystallization of the mayor component (case b) can be considered the most frequent, while isomorphic behavior is the less common. ${ }^{14}$

As far as we know, there are no general rules that can unambiguously predict if a copolymer will display isomorphic, isodimorphic or no co-crystallization ${ }^{14}$. In fact, even in those cases where the comonomers have similar chemical structures and are miscible in the amorphous phase, the possibility of forming a mixed crystalline unit cell, or in other words the efficiency of comonomer inclusion, is not easily determined. While co-crystallization has been already demonstrated in 
some specific type of polyesters or polycarbonates, as far as the authors are aware this crystallization phenomenon has not been seen in other type of polymer families. ${ }^{15-19}$

Herein, we expanded the concept of NEMO catalyzed bulk self-condensation of diols to prepare a set of copolyethers based on 1,6-hexanediol and 1,12-dodecanediol. The obtained poly(oxyhexamethylene-ran-oxydodecamethylene) copolyethers were characterized in terms of molecular weight and composition. The thermal properties and crystallization behavior were studied in detail by DSC and WAXS. The copolyethers showed the ability to crystallize in all the composition range in a single crystal structure while their single melting transition followed a simple rule of mixing. This is the typical behavior of isomorphic crystallization and the effect of the composition of comonomer units on the crystalline structure was then investigated. To our knowledge, this is the first report on aliphatic copolyethers showing isomorphism. Moreover, a random terpolymer was also synthesized and it showed similar thermal behavior, suggesting that this chemistry could be further expanded to other copolymers to tune the thermal properties on demand.

\section{EXPERIMENTAL SECTION}

\section{Materials and Methods}

\section{Materials}

1,12-Dodecanediol (99\%, Sigma-Aldrich), 1,10-decanediol (99\%, Sigma-Aldrich) and 1,6-hexanediol (99\% Sigma-Aldrich), were used as received after being dried in toluene. Methanesulfonic acid (MSA, 99\%) and 1,5,7-triazabicyclo[4.4.0]dec-5-ene (TBD, 98\%), 
chloroform $\left(\mathrm{CDCl}_{3}\right)$, methanol $\left(\mathrm{CH}_{3} \mathrm{OH}\right)$ and the rest of the solvents used on this work were supplied by Sigma-Aldrich and used as received.

\section{Methods}

\section{${ }^{1} \mathrm{H}$ and ${ }^{13} \mathrm{C}$ Nuclear Magnetic Resonance (NMR) spectroscopies}

${ }^{1} \mathrm{H}$ Nuclear Magnetic Resonance (NMR) spectra were used for analyzing the non-eutectic acid base organocatalyst, the monomer conversions and the copolymer final composition. ${ }^{13} \mathrm{C}$ Nuclear Magnetic Resonance (NMR) spectra was used for determining the microstructure of the copolyethers and the terpolyether prepared here.

${ }^{1} \mathrm{H}$ and ${ }^{13} \mathrm{C}$ Nuclear Magnetic Resonance (NMR) spectra Nuclear Magnetic Resonance (NMR) spectra were recorded in a Bruker Advance DPX 300 at $300.16 \mathrm{MHz}$ and at $75.5 \mathrm{MHz}$ of resonance frequency respectively, using DMSO and $\mathrm{CDCl}_{3}$ as solvents at room temperature. Experimental conditions were as follows: (a) for ${ }^{1} \mathrm{H}$ NMR spectroscopy: $10 \mathrm{mg}$ of sample; $3 \mathrm{~s}$ acquisition time; $1 \mathrm{~s}$ delay time; $8.5 \mu$ s pulse; spectral width $5000 \mathrm{~Hz}$ and 32 scans; (b) for ${ }^{13} \mathrm{C}$ NMR spectroscopy: $40 \mathrm{mg} ; 3 \mathrm{~s}$ acquisition time; $4 \mathrm{~s}$ delay time; $5.5 \mu$ s pulse; spectral width 18,800 $\mathrm{Hz}$ and more than 10,000 scans.

\section{Size exclusion chromatography analysis (SEC)}

The molecular weights of the copolymers were determined by SEC analysis (Agilent PLGPC 50) using Shodex GPC HFIP-803 (300 x 8.0mm) with chloroform as the eluent, at $50{ }^{\circ} \mathrm{C}$ and a flow rate of $1 \mathrm{~mL} \mathrm{~min}{ }^{-1}$ with polystyrene standards. 


\section{Differential Scanning Calorimetry (DSC)}

A Perkin-Elmer Differential Scanning Calorimeter, DSC 8500, was used to determine the thermal behavior of the samples. The DSC scans were collected employing 4.5-5.5 mg samples at heating and cooling rates of $20{ }^{\circ} \mathrm{C} / \mathrm{min}$ from -60 to $150{ }^{\circ} \mathrm{C}$ under a nitrogen flow of $20 \mathrm{~mL} / \mathrm{min}$. Indium and tin standards were utilized to calibrate the equipment. The second heating scans provide the values of the melting temperature $\left(T_{m}\right)$, as well as the latent heat of melting $\left(\Delta H_{m}\right)$ reported. The cooling scans from the melt give the crystallization temperature $\left(T_{c}\right)$ and the latent heat of crystallization $\left(\Delta H_{C}\right)$.

\section{Wide-Angle X-ray Scattering (WAXS)}

Before the measurement by WAXS, the samples had a previous thermal treatment. The sample was first melted at $\mathrm{Tx}\left(\mathrm{Tx}\right.$ is a temperature $40{ }^{\circ} \mathrm{C}$ above the melting temperature of the material) to erase thermal history, then it was cooled at $20{ }^{\circ} \mathrm{C} / \mathrm{min}$ from Tx to $15{ }^{\circ} \mathrm{C}$ to allow all samples to crystallize, and finally heated at $20{ }^{\circ} \mathrm{C} / \mathrm{min}$ from $15^{\circ} \mathrm{C}$ to room temperature $\left(25^{\circ} \mathrm{C}\right)$. A constant scanning rate of $20^{\circ} \mathrm{C} / \mathrm{min}$ was used for DSC cooling and heating scans.

WAXS was performed at the beam line BL11-NCD in the ALBA Synchrotron radiation facility (Barcelona, Spain) to the samples with the indicated thermal treatment. The samples were measured inside DSC pans. In a Linkam THMS600 hot stage coupled to a liquid nitrogen cooling system, the WAXS patterns were collected at $25^{\circ} \mathrm{C}$. The energy of X-ray source was $12.4 \mathrm{kV}$ $(\lambda=1.0 \AA)$. WAXS patterns were recorded using a Rayonix LX255-HS detector with an active area of 85 x $255 \mathrm{~mm}^{2}$ (pixel size 40x40 $\mu^{2}$ ), the sample-to-detector distance employed was 196.14 $\mathrm{mm}$ with a tilt angle of $30.33^{\circ}$. The intensity profile is reported as the plot of the scattering intensity vs scattering vector. The scattering vector was calibrated using silver chromium (III) oxide. 


\section{Synthesis}

The synthesis of copolyethers was performed by self-condensation of two different diols: a short chain aliphatic diol (1,6-hexanediol) and a long chain one (1,12-dodecanediol). The copolymers were named as C6/C12 mol\% as the molar percentage of 1,6-hexanediol and 1,12dodecanediol used in the feed.

In the first step the NEMOs were prepared by simple non-stoichiometric mixture (3:1) of methanesulfonic acid (MSA) and 1,5,7-triazabicyclo[4.4.0]dec-5-ene (TBD). The mixtures were thermally treated at $90{ }^{\circ} \mathrm{C}$ over 30 minutes under stirring until complete formation of homogeneous and transparent liquid solution. After the catalyst preparation, a mixture of monomers containing different 1,6-hexanediol/1,12-dodecanediol (C6/C12) ratios: 90/10 (4.20 g, 0.036 mol/0.80 g, 3.95 $10^{-3} \mathrm{~mol}$ ), 85/15 (3.84 g, $\left.0.032 \mathrm{~mol} / 1.16 \mathrm{~g}, 5.7310^{-3} \mathrm{~mol}\right), 70 / 30$ (2.88 g, $0.024 \mathrm{~mol} / 2.12 \mathrm{~g}, 0.010$ mol), 60/40 (2.33 g, 0.020 mol/2.67 g, $0.013 \mathrm{~mol}), 50 / 50$ (1.84 g, 0.016 mol/3.16g, 0.016 mol), 40/60 (1.40 g, $0.012 \mathrm{~mol} / 3.60 \mathrm{~g}, 0.018 \mathrm{~mol})$, 30/70 (1.00 g, $\left.8.4710^{-3} \mathrm{~mol} / 4.00 \mathrm{~g}, 0.020 \mathrm{~mol}\right)$ and were added respectively to 0.05 equiv. organocatalyst. Likewise, for the synthesis of the terpolymer, a mixture of monomers contained (C6/C10/C12) 33/33/33: 0.010 mol (1.194 g/1.761 g/ 2.045 g) was also added also with 0.05 equiv. organocatalyst.

The sealed reaction vessels were then submerged into a pre-heated oil bath at $130{ }^{\circ} \mathrm{C}$ under vacuum. The self-condensation process was performed in three steps. After the first $24 \mathrm{~h}$ at 130 ${ }^{\circ} \mathrm{C}$ the temperature was increased to $180{ }^{\circ} \mathrm{C}$ for $24 \mathrm{~h}$ and to $200{ }^{\circ} \mathrm{C}$ for the last $24 \mathrm{~h}$. After completion, the copolyethers were cooled to room temperature naturally. For the purification, the samples were dissolved in chloroform and precipitated in cold methanol. The resulted copolyethers were filtrated and dried under vacuum at RT for $24 \mathrm{~h}$ before their characterization. Homopolymers 
from 1,6-hexanediol 1,10-decanediol and 1,12-dodecanediol were synthesized and purified by the same procedure.

\section{RESULTS AND DISCUSSION}

\section{Synthesis and characterization of poly(oxyhexamethylene-co-oxydodecamethylene)}

\section{copolyethers}

Recently we reported the bulk self-condensation of aliphatic diols as a route to aliphatic polyether homopolymers. ${ }^{13}$ Following a similar procedure, a series of copolyethers with different compositions were synthesized by self condensation of 1,6-hexanediol and 1,12-dodecanediol (Scheme 1). The Non-Eutectic Mixture Organocatalyst (NEMO) formed through the proton transfer of methanesulfonic acid (MSA) and 1,5,7 triazabicyclo[4.4.0]dec-5-ene (TBD) was used as catalyst.

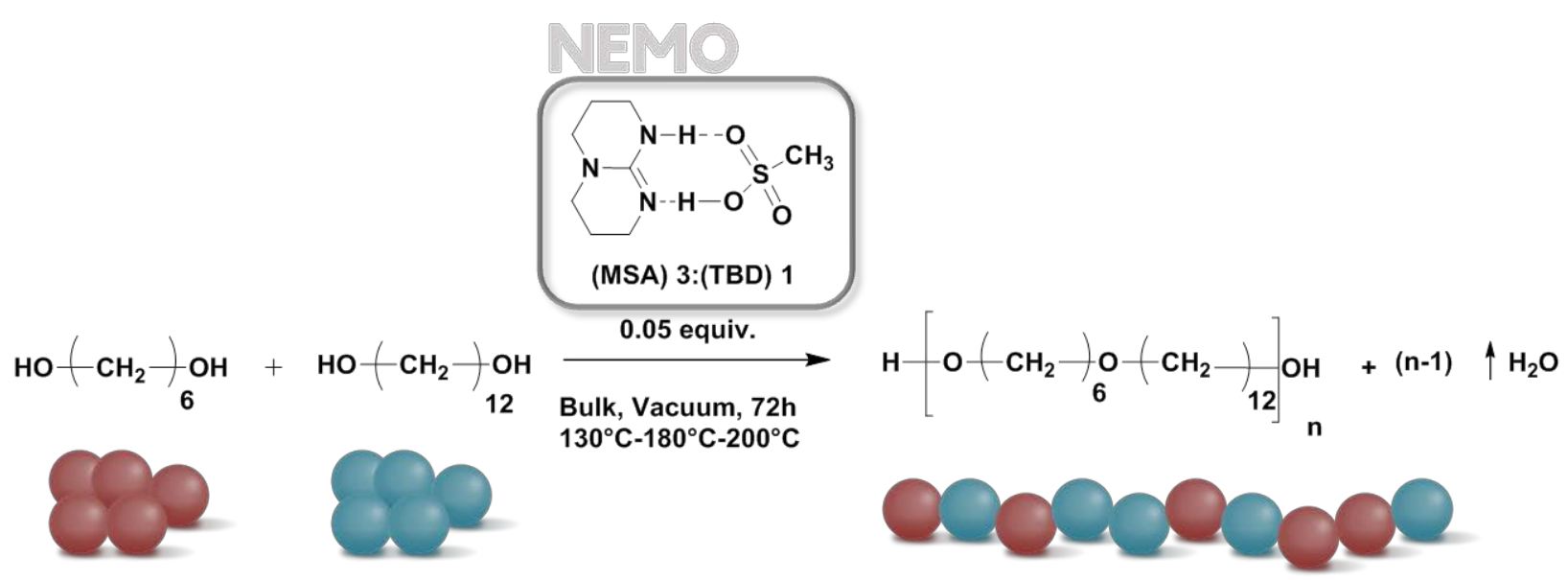

Scheme 1. Synthesis route of random copolyethers from 1,6-hexanediol and 1,12-dodecanediol in bulk conditions using MSA:TBD (3:1) as NEMO. 
In a typical reaction, the correspondent ratios of 1,6-hexanediol and 1,12-dodecanediol were added in the presence of NEMO organocatalysts. The polymerization reaction was carried out in various steps, first at $130{ }^{\circ} \mathrm{C}$ for $24 \mathrm{~h}$, after which the temperature was raised to $180{ }^{\circ} \mathrm{C}$ for $48 \mathrm{~h}$ under vacuum mimicking the conditions used in other polycondensations. The copolymerizations were monitored using ${ }^{1} \mathrm{H}$ NMR by the diagnostic disappearance of 1,6hexanediol and 1,12-dodecanediol methylene protons (signal $\delta 3.65 \mathrm{ppm}$, adjacent to the alcohol) and their subsequent reappearance at $\delta 3.33 \mathrm{ppm}$ due to ether formation. High conversion values were obtained in all cases.

When the reaction finished after $72 \mathrm{~h}$ the molar composition of the copolyethers were calculated from the ${ }^{1} \mathrm{H}$ NMR spectrum using the relative intensities of the proton signals arising from the 1,6-hexanediol and 1,12-dodecanediol repeating units pointed out as signal 3 (red) and 3, 4, 5, 6 (blue) respectively (Figure 1). It was observed that the content of 1,6-hexanediol was slightly lower in the copolymer composition than in the original feed. This small deviation of about $10 \%$ (Table 1) could be attributed to the short length of 1,6-hexanediol respect to 1,12dodecanediol and the possible cycle formation or monomer distillation during the reaction. SEC chromatograms showed monomodal distribution confirming the copolymerization of both comonomers in a single polymer. 
(a)
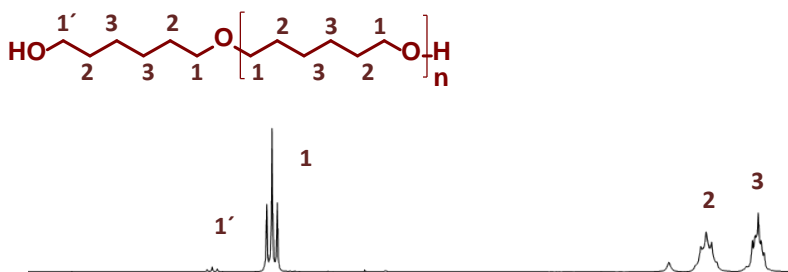

(b)

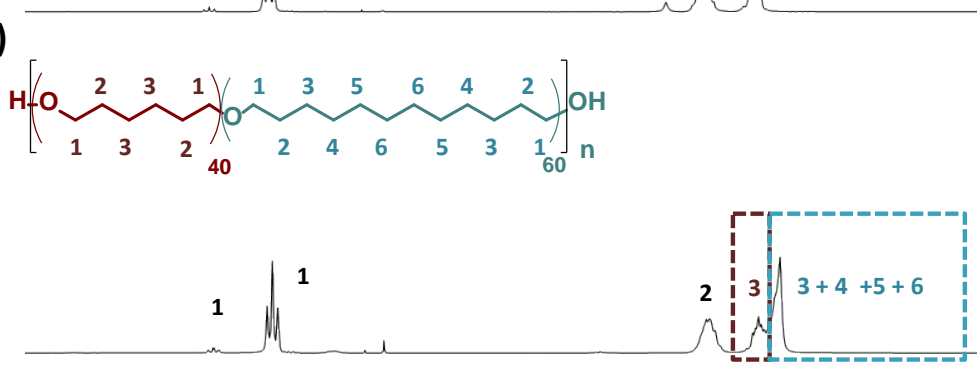

(c)
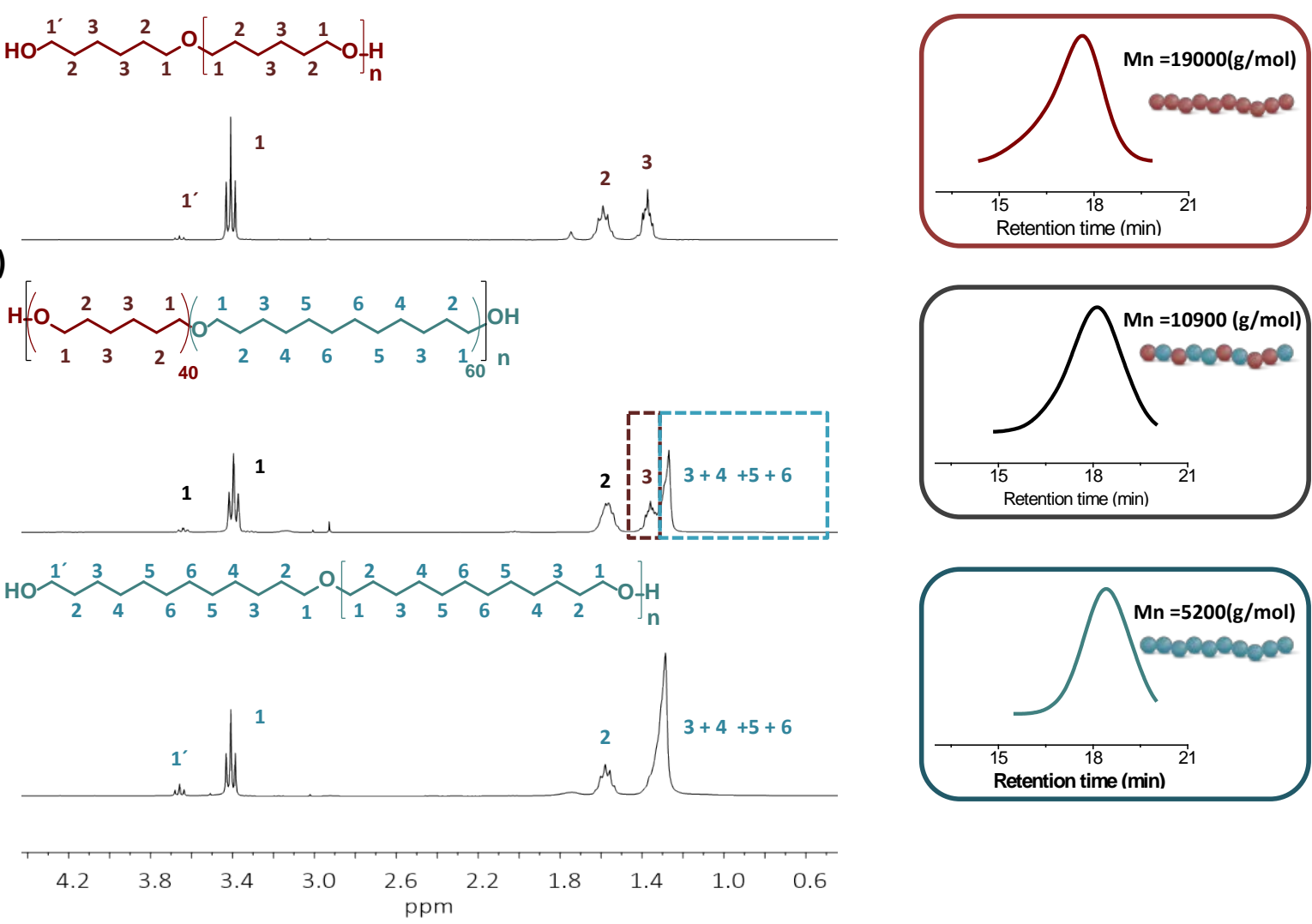

Figure 1. ${ }^{1} \mathrm{H}$ NMR spectrum and SEC traces of a) poly(oxyhexamethylene) homopolymer, b) poly(oxyhexamethylene-co-oxydodecamethylene) copolymer $40 / 60$ and

c) poly(oxydodecamethylene) homopolymer. 
$\left.\mathrm{H}-\mathrm{O}\left(-\mathrm{CH}_{2}-\mathrm{CH}_{2}-\mathrm{CH}_{2}-\mathrm{CH}_{2}-\mathrm{CH}_{2}-\mathrm{CH}_{2}\right) \mathrm{O}\left(\mathrm{CH}_{2}-\mathrm{CH}_{2}-\mathrm{CH}_{2}-\mathrm{CH}_{2}-\mathrm{CH}_{2}-\mathrm{CH}_{2}-\mathrm{CH}_{2}-\mathrm{CH}_{2}-\mathrm{CH}_{2}-\mathrm{CH}_{2}-\mathrm{CH}_{2}-\mathrm{CH}_{2}\right)\right] \mathrm{OH}$

(a)

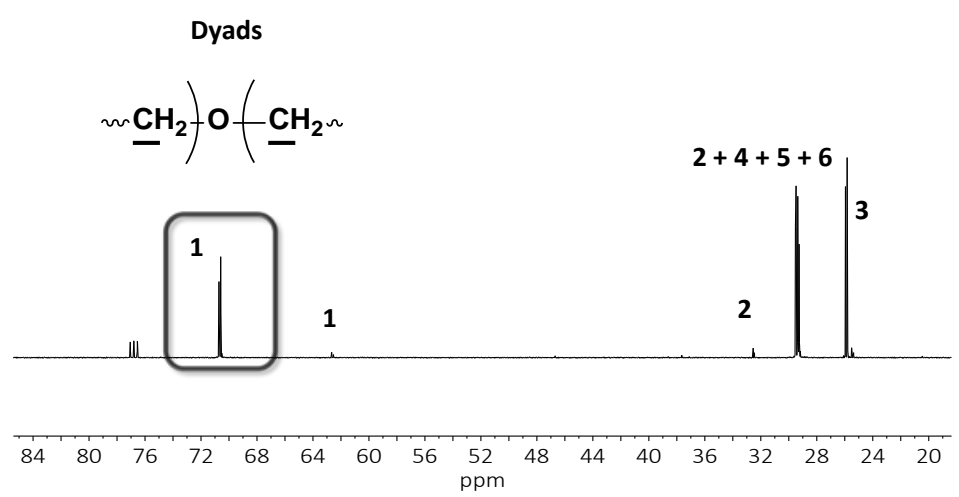

(b)

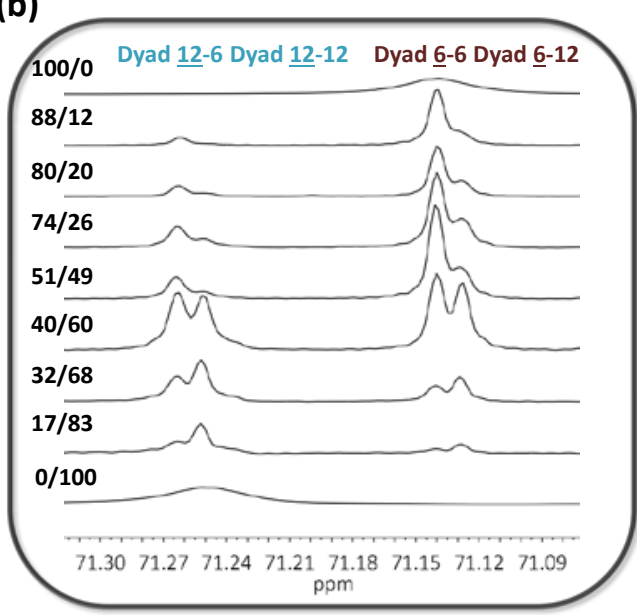

Figure 2. a) Chemical structure and ${ }^{13} \mathrm{C}$ NMR spectrum of the copolyether (40/60) and b) region of the methylene carbons used for the $\mathrm{R}$ value determination

The microstructure (random, alternating or blocky) of the copolymer significantly influences the final properties and is a key factor for crystallization. To get a better understanding of the polymer microstructure and to evaluate the randomness character of the copolymers, we analyzed the copolymers using ${ }^{13} \mathrm{C}$ NMR spectroscopy.

As an example, Figure 2 shows the ${ }^{13} \mathrm{C}$ NMR spectrum of the copolymer C6/C12(40/60) and the scale expanded region of the methylene carbons close to the ether linkage. In both homopolymers, only one signal attributed to these carbons was observed. When the co-monomers are copolymerized, new signals were observed, along with those previously mentioned. These new signals are attributed to the presence of different dyads. Thus, the chemical shift of the methylene group linked to the ether bond would be influenced by the adjacent group (region 71.10-71.30 ppm). These dyads were named as dyad ${ }_{\underline{12}-6}, \operatorname{dyad}_{\underline{12}-12}$ and $\operatorname{dyad}_{\underline{6}-6}, \operatorname{dyad}_{\underline{6}-12}$, which appear at $\delta 71.26$ 
ppm, 71.25 ppm, 71.14 ppm and 71.13 ppm, respectively. Based on the ${ }^{13} \mathrm{C}$ NMR spectra, the relative molar fraction of the interchange dyad, (C6-C12), can be easily determined and the randomness character value $(R)$ of the copoyethers was calculated using the following equation (1):

$$
R=\frac{(\mathrm{C} 6-12)}{2(\mathrm{C} 6)(\mathrm{C} 12)}(1)
$$

Depending on the value of $R$, the copolymer can be considered blocky, random or alternate. The values of $R$ tend to in each case to 0,1 or 2 , respectively. Thus, as summarized in Table 1 , the degree of randomness was 1 or very close to it indicating the random nature of the prepared copolymers.

Table 1. Molecular characteristics of the copolyethers.

\begin{tabular}{|c|c|c|c|c|c|c|}
\hline Entry & $\begin{array}{l}\text { (C6)/(C12) \% in the } \\
\text { feed }\end{array}$ & $\begin{array}{l}(\mathrm{C} 6) /(\mathrm{C} 12) \% \text { in the } \\
\text { polymer }^{\text {a }}\end{array}$ & $\begin{array}{l}M_{n}^{\mathrm{a}} \\
(\mathrm{g} / \mathrm{mol})\end{array}$ & $\begin{array}{l}M_{n}^{\mathrm{b}} \\
(\mathrm{g} / \mathrm{mol})\end{array}$ & $D$ & $R^{\mathrm{C}}$ \\
\hline 1 & $100 / 0$ & - & 10000 & 19000 & 2.0 & - \\
\hline 3 & $90 / 10$ & $88 / 12$ & 10100 & 17400 & 2.1 & 1.04 \\
\hline 4 & $85 / 15$ & $80 / 20$ & 8900 & 16700 & 2.2 & 0.95 \\
\hline 6 & $70 / 30$ & $74 / 26$ & 4200 & 11100 & 2.4 & 1.01 \\
\hline 7 & $60 / 40$ & $51 / 49$ & 4000 & 10900 & 2.0 & 0.96 \\
\hline 8 & $50 / 50$ & $40 / 60$ & 3600 & 7200 & 2.4 & 1.01 \\
\hline 10 & $40 / 60$ & $32 / 68$ & 3500 & 6100 & 2.0 & 0.95 \\
\hline 11 & $30 / 70$ & 17/83 & 2800 & 5900 & 2.1 & 0.96 \\
\hline 14 & $0 / 100$ & - & 3200 & 5200 & 2.2 & - \\
\hline
\end{tabular}


${ }^{1} \mathrm{H}$ NMR spectroscopy and SEC analysis were used to determine the molecular weight of all the copolymers. By ${ }^{1} \mathrm{H}$ NMR the values were calculated taking into account the final copolymer composition and by the integration of the methylene end group close to the alcohol that shows a peak at $3.65 \mathrm{ppm}$ and the signal adjacent to the ether linkage at $\delta 3.33 \mathrm{ppm}$.

The molecular weight of the copolyethers increased from 5900 to 17400 as the 1,6 hexanediol content increases. This trend is in agreement with the molecular weight values of the homopolymers, which are lower for poly(oxydodecamethylene). The reason for these differences in molecular weight could be attributed to the increase in melt viscosity of the copolyethers as the number of methylene units in the chain increases. When the viscosity increases, water diffusion and subsequent chain growth are lower and the extent of the step-growth polymerization is limited. ${ }^{13}$ We also observed that the molecular weights measured by SEC employing polystyrene standards were higher than those calculated by NMR. Interestingly, they followed the same trend, higher molecular weights were obtained when the content of 1,6 hexanediol increased. In all cases, the SEC chromatograms of the copolymers showed a dispersity close to 2, common for stepgrowth polymerization materials (Figure $1 \mathrm{~d}){ }^{20}$

\section{Thermal Characterization of poly(oxyhexamethylene-co-oxydodecamethylene)}

\section{copolyethers}

The crystallization behavior of the random copolymers was investigated by differential scanning calorimetry (DSC) and compared to that of homopolyethers. Figure 3a shows the behavior of the materials when they were cooled from the melt, a single crystallization peak is observed for all compositions. When analyzing the subsequent DSC heating scans (Figure 3b), a single melting peak is also observed for the whole series of copolyethers. For both crystallization 
and melting transitions, the peak values corresponding to $T_{m}$ and $T_{c}$ strongly depend on the composition (C6/C12) present in each copolyether.
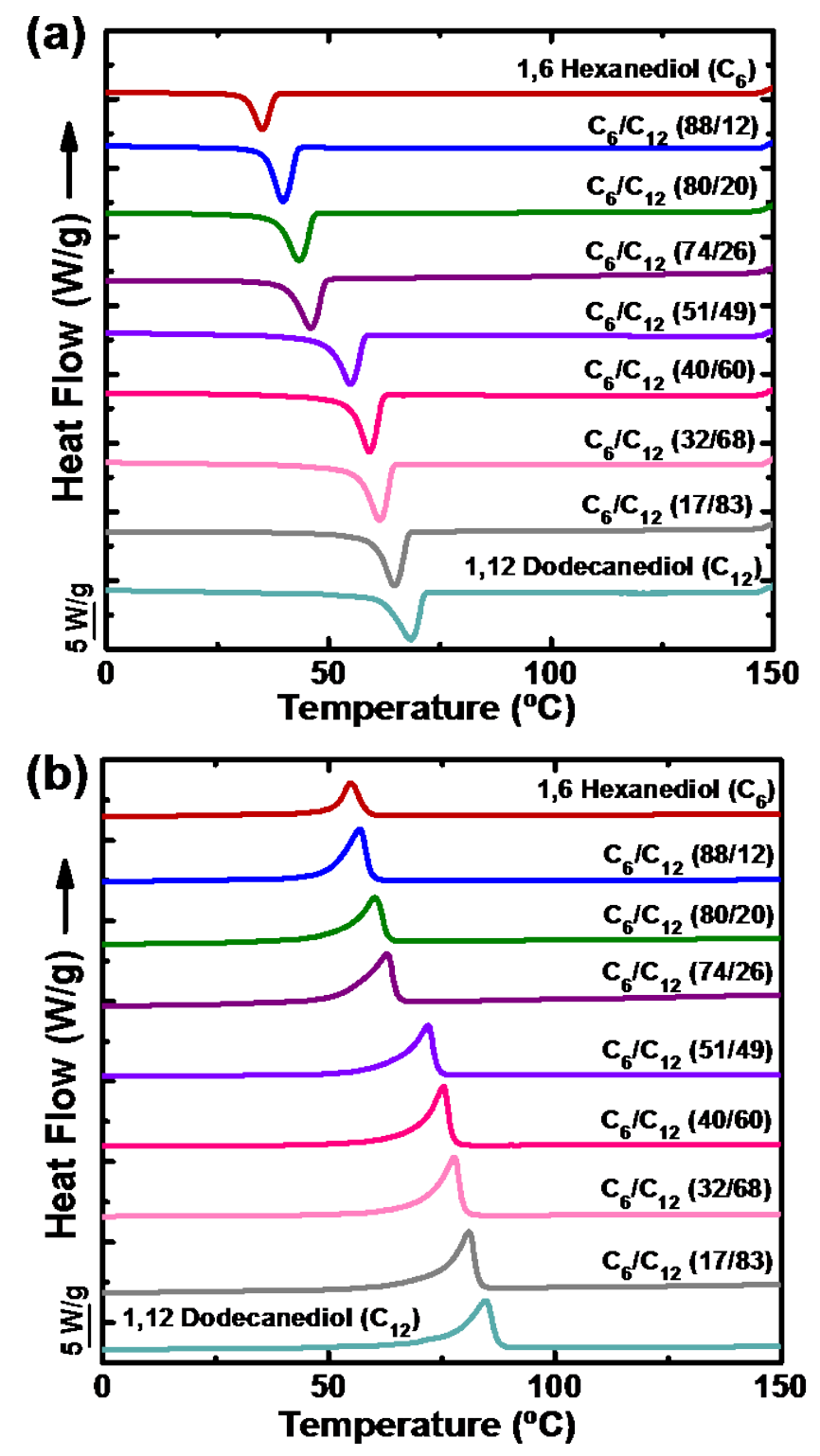

Figure 3. (a) Cooling DSC scans from the melt and (b) subsequent heating scans for the indicated polyethers and copolyethers.

Table 2 shows that $T_{m}$ and $T_{c}$ values for the copolyethers increase from the characteristic values of poly(oxyhexamethylene) to those of poly(oxydodecamethylene) in a monotonic trend 
with composition. Figure 4 shows an almost linear trend in the increase of $T_{m}$ and $T_{c}$ when the amount of 1,12-dodecanediol increases. It is remarkable that a single first order crystallization or melting transition is observed in the copolyethers at temperatures in between those of the corresponding homopolymers. Furthermore, despite the fact that the copolymers are random, the prepared copolyethers can crystallize in the entire composition range. These observations can only be possible if comonomer inclusion inside the formed crystals dominates over comonomer exclusion. In other words, the prepared copolymers are probably isomorphic. ${ }^{14}$

Table 2. Thermal Properties of the Copolyethers.

\begin{tabular}{llllll}
\hline Polymer & $T_{c}\left({ }^{\circ} \mathrm{C}\right)$ & $\Delta H_{c}(\mathrm{~J} / \mathrm{g})$ & $T_{m}\left({ }^{\circ} \mathrm{C}\right)$ & $\Delta H_{m}(\mathrm{~J} / \mathrm{g})$ & $X c^{*}$ \\
\hline Poly(oxyhexamethylene) & 35.0 & -75 & 54.9 & 83 & 0.33 \\
\hline C6/C12 (88/12) & 39.7 & -123 & 56.8 & 133 & 0.53 \\
\hline C6/C12 (80/20) & 43.3 & -129 & 60.2 & 139 & 0.55 \\
\hline C6/C12 (74/26) & 46.0 & -137 & 62.9 & 145 & 0.57 \\
\hline C6/C12 (51/49) & 54.8 & -141 & 71.9 & 152 & 0.58 \\
\hline C6/C12 (40/60) & 59.0 & -150 & 75.3 & 161 & 0.62 \\
\hline C6/C12 (32/68) & 61.4 & -157 & 77.7 & 164 & 0.62 \\
\hline C6/C12 (17/83) & 64.7 & -150 & 80.9 & 164 & 0.62 \\
\hline Poly(oxydodecamethylene) & 68.4 & -157 & 84.7 & 166 & 0.62 \\
\hline *Calculated by $X_{c}=\Delta H_{m} / \Delta H_{m}{ }^{o}{ }^{*}(6 / C 12)$, & see Supporting Information. &
\end{tabular}

According to the behavior described above (see Figure 4), the copolyethers prepared here display thermal properties typical of isomorphic random copolymers. Two classes of isomorphism have been reported: a) chain isomorphism and b) isomorphism of monomeric units. As we are 
dealing with random copolyethers, we will focus on the isomorphism of comonomer units. Isomorphism among monomeric units occurs in copolymerizing monomers that have a chemical nature and shape slightly different one another (e.g., styrene and o-fluorostyrene). This allows the formation of crystallizable copolymers in the entire composition range. They show physical properties (lattice constants, melting temperatures, etc.) continuously varying between those of the pure homopolymers. ${ }^{15,17}$

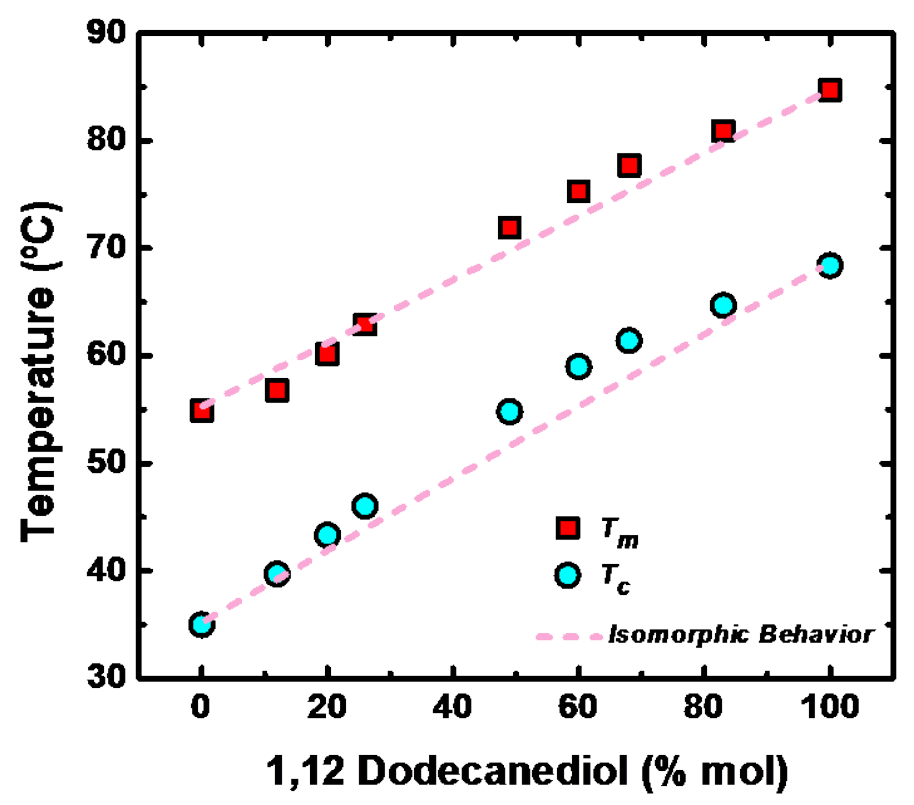

Figure 4. Values of $T_{m}$ and $T_{c}$ as a function of 1,12-dodecanediol content in the copolyether.

To further confirm the isomorphic behavior of the studied copolymers, they must fulfill requirements that are observed in isomorphic random copolymers. ${ }^{15,18,19,21,22}$ One essential requirement is that the copolymers must have approximately the same shape, volume and compatible conformations of the different comonomer units. In the case of the copolyethers analyzed in this paper, these polymers are made from two homopolyethers, whose chemical 
structure only differs in the number of methylene units present in the main chain, so it is probable that they fulfil this requirement (as will be confirmed by WAXS studies below).

In Figure 4, the series of copolymers show single crystallization and melting peaks at intermediate temperatures between those of the homopolymers of reference. This behavior is reported for copolymers of isomorphic comonomeric units and is attributed to the fact that both homopolymers are crystalline and show the same symmetry. ${ }^{17-19,21}$ Moreover, both transitions increase when the content of 1,12-dodecanediol in the copolymer is increased.

The isomorphic copolymers show a peculiar behavior in their thermal properties when these are plotted as a function of composition. ${ }^{14,15,17-19,21,22}$ Figure 6 shows the values of $T_{m}$ as a function of composition (i.e., 1,12-dodecanediol content), where the experimental results approximately fit a straight line connecting the $T_{m}$ of the two homopolymers (dotted pink line), i.e., a simple mixing law. Similar behaviors have been reported in the literature for random copolymers where two different comonomers form an isomorphic substitution. ${ }^{15,17-19,21,22}$ On the other hand, Table 2 shows enthalpy values (and therefore crystallinity values calculated there from) in between those of the homopolyethers for all compositions, indicating that the 1,6hexanediol and 1,12-dodecanediol units co-crystallize, as there is no decrease in the crystallinity degree (expected when exclusion from the crystal lattice takes place).

An additional requirement for isomorphism is that the crystalline phases of the two homopolymers must be analogous from the point of view of conformation of the chains and the symmetry of the lattice dimensions. Only in this case, a single crystalline phase would be possible with small continuous dimensional changes depending on the composition. ${ }^{15,21}$ Kobayashi et al. reported that both homopolyether chains employed here, poly(oxyhexamethylene) and poly(oxydodecamethylene), have essentially a planar zigzag chain conformation in the crystal. ${ }^{10}$ 
On the other hand, poly(oxyhexamethylene) can present two forms of crystal packing (monoclinic and orthorhombic) or a mixture of both depending on the crystallization conditions. Poly(oxydodecamethylene), on the other hand, crystallizes with an orthorhombic unit cell. Regarding the symmetry of the polyethers, it is observed that depending on the number of methylene groups in the chain (even or odd) they present different types of symmetry. Poly(oxyhexamethylene) and poly(oxydodecamethylene) have both even numbers of methylene groups, therefore they both have the same symmetry. Kobayashi et al. also report the unit cell dimensions for orthorhombic poly(oxydodecamethylene): a=7.40 $\AA, b=4.94 \AA$ and c=32.53 $\AA$; and for monoclinic poly(oxyhexamethylene): $a=5.65 \AA, b=9.01 \AA$ and $c=17.28 \AA .{ }^{10}$ No reports can be found in the literature for the unit cell dimensions of the orthorhombic polymorph of poly(oxyhexamethylene).

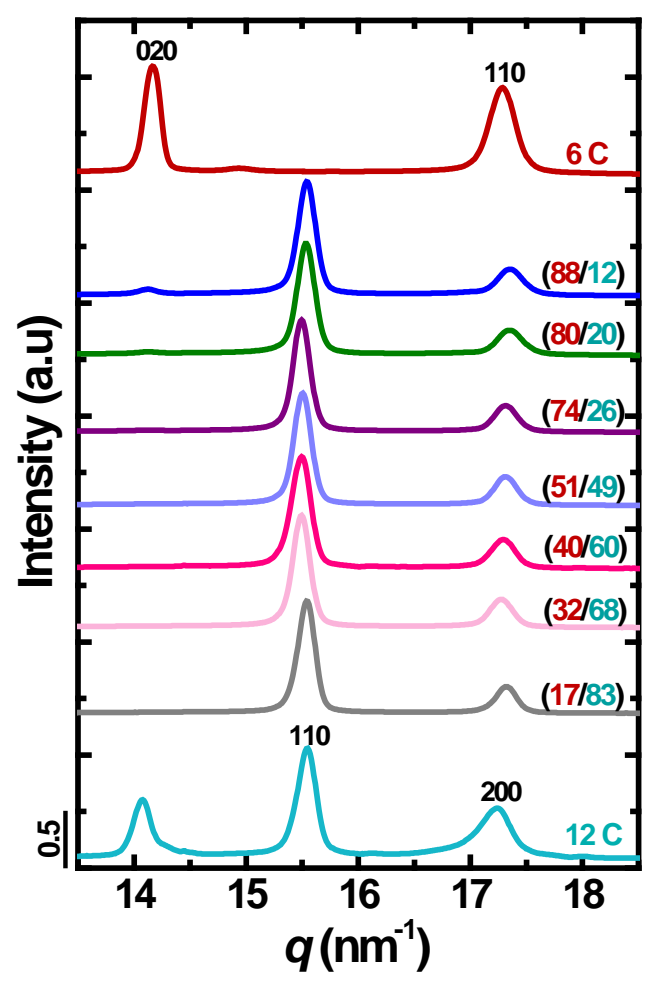

Figure 5. WAXS diffraction patterns for copolyethers at $25^{\circ} \mathrm{C}$. 
Although the dimensions of both homopolyethers unit cells are not similar, it is necessary to remember that the poly(oxyhexamethylene) can also crystallize in an orthorhombic unit cell. It could be possible that in the copolyether, both comonomeric units form a single orthorhombic unit cell. This crystalline unit cell could resemble the unit cell of polyethylene, as it is known that polyether chains with long methylene sequences tend to form orthorhombic unit cells that are similar to that of polyethylene. ${ }^{10,23}$

Figure 5 shows the WAXS patterns obtained for all the prepared copolyethers and homopolyethers at $25^{\circ} \mathrm{C}$, after they were crystallized non-isothermally at $20^{\circ} \mathrm{C} / \mathrm{min}$. It can be seen that the homopolymers poly(oxyhexamethylene) and poly(oxydodecamethylene) show characteristic and distinct reflections that correspond to their reported monoclinic and orthorhombic unit cells. ${ }^{10}$

The reflections obtained for poly(oxyhexamethylene) at $q$ values of 14.16 and $17.29 \mathrm{~nm}^{-1}$, correspond to the (020) and (110) crystal planes. In the case of poly(oxydodecamethylene), the reflections at $q$ values of 15.55 and $17.24 \mathrm{~nm}^{-1}$ correspond to the (110) and (200) crystal planes. The calculated interplanar distances are reported in Table 3 and they are similar to literature values. ${ }^{10}$ There is an additional reflection in the case of poly(oxydodecamethylene) at a $q$ value of $14.08 \mathrm{~nm}^{-1}$ corresponding to an interplanar distance $\left(\mathrm{d}_{h k l}\right)$ of $4.46 \AA$ A. Further crystallographic work would be needed in order to reveal the origin of this reflection, which is outside the scope of the present paper.

For the copolyethers, Figure 6 shows that all compositions prepared exhibit crystalline reflections at $q$ values of approximately 15.5 and 17.3 that should correspond to diffraction from (110) and (200) crystal planes respectively. These two reflections resemble those observed for poly(oxydodecamethylene) at similar $q$ values (see Figure 6 and Table 3). The results suggest that 
all copolyethers crystallize with a single unit cell, and this unit cell resembles that formed by poly(oxydodecamethylene).

Table 3. Calculated Interplanar Distance $\left(\mathrm{d}_{h k l}\right)$ from Figure 5 and comparison with reported values $^{10}$

\begin{tabular}{|c|c|c|c|c|c|c|}
\hline Polymer & $2 \theta$ & $q\left(\mathrm{~nm}^{-1}\right)$ & $d_{h k l}(\AA)$ & $q\left(\mathrm{~nm}^{-1}\right)^{\mathrm{a}}$ & $d_{h k l}(\AA)^{\mathrm{a}}$ & Reflection \\
\hline \multirow{2}{*}{ Poly(oxyhexamethylene) } & 13.33 & 14.16 & 4.436 & 13.94 & 4.507 & 020 \\
\hline & 16.29 & 17.29 & 3.635 & 17.08 & 3.678 & 110 \\
\hline \multirow{2}{*}{ C6/C12 (88/12) } & 14.64 & 15.54 & 4.042 & - & - & 110 \\
\hline & 16.36 & 17.36 & 3.620 & - & - & 200 \\
\hline \multirow{2}{*}{ C6/C12 (80/20) } & 14.63 & 15.53 & 4.045 & - & - & 110 \\
\hline & 16.35 & 17.35 & 3.621 & - & - & 200 \\
\hline \multirow{2}{*}{ C6/C12 (74/26) } & 14.59 & 15.49 & 4.056 & - & - & 110 \\
\hline & 16.32 & 17.32 & 3.628 & - & - & 200 \\
\hline \multirow{2}{*}{ C6/C12 (51/49) } & 14.60 & 15.50 & 4.053 & - & - & 110 \\
\hline & 16.32 & 17.31 & 3.629 & - & - & 200 \\
\hline \multirow{2}{*}{ C6/C12 (40/60) } & 14.59 & 15.50 & 4.055 & - & - & 110 \\
\hline & 16.30 & 17.30 & 3.632 & - & - & 200 \\
\hline \multirow{2}{*}{ C6/C12 (32/68) } & 14.59 & 15.49 & 4.055 & - & - & 110 \\
\hline & 16.28 & 17.28 & 3.636 & - & - & 200 \\
\hline \multirow{2}{*}{ C6/C12 (17/83) } & 14.64 & 15.54 & 4.043 & - & - & 110 \\
\hline & 16.33 & 17.33 & 3.627 & - & - & 200 \\
\hline \multirow{3}{*}{ Poly(oxydodecamethylene) } & 13.25 & 14.08 & 4.464 & 13.87 & 4.530 & - \\
\hline & 14.64 & 15.55 & 4.041 & 15.34 & 4.096 & 110 \\
\hline & 16.25 & 17.24 & 3.645 & 17.05 & 3.686 & 200 \\
\hline
\end{tabular}




\begin{tabular}{ccccccc}
\hline Polyethylene $^{\mathrm{b}}$ & - & - & - & 15.26 & 4.115 & 110 \\
& - & - & - & 16.96 & 3.703 & 200 \\
\hline
\end{tabular}

a,b ${ }^{\text {Reference values }}{ }^{24,25}$

Table 3 shows the values obtained in this work for the interplanar distances $\left(d_{h k l}\right)$ of the copolyethers. As these are new materials, there are no values reported in the literature for comparison purposes. However, the interplanar distances obtained are comparable to those reported for orthorhombic polyethylene and also to our poly(oxydodecamethylene) (see Table 3).

From the above results it is obvious that a single orthorhombic unit cell is formed in the copolyethers, corroborating that the copolymers prepared here have an isomorphic behavior. Furthermore, when analyzing the values of the interplanar distance $\left(d_{h k l}\right)$, calculated using Bragg's law, versus the composition (Figure 6), these $d_{h k l}$ values also change linearly with composition but the observed change is very small. A similar behavior has been reported for systems with isomorphic substitution, which is also an indication that the random copolyethers synthesized here are isomorphic. $^{19}$ 


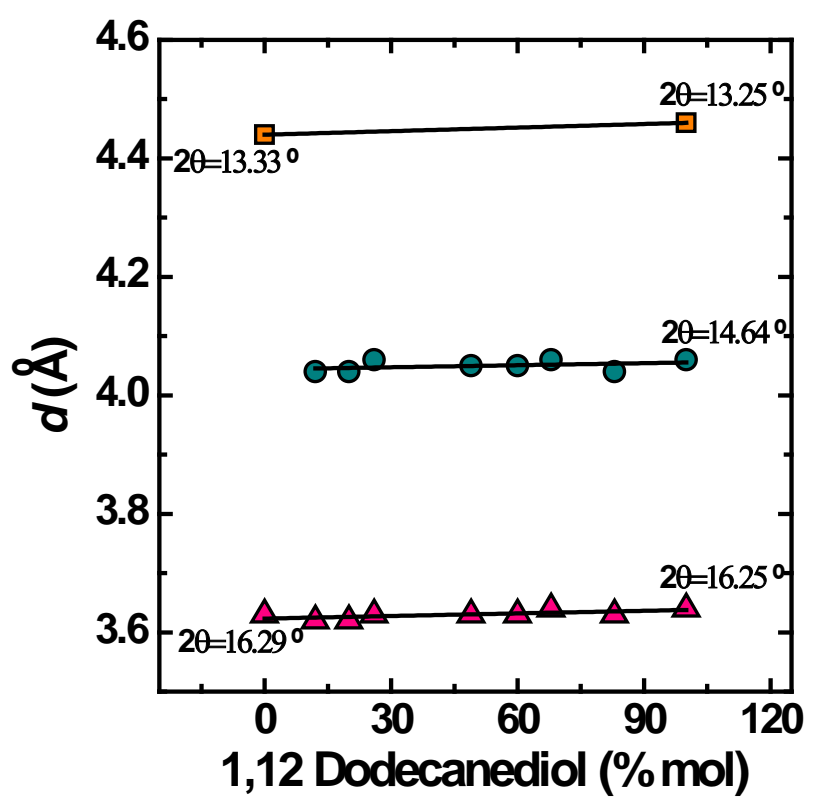

Figure 6. Interplanar distance $\left(d_{h k l}\right)$ for all reflections at $25^{\circ} \mathrm{C}$.

Provided that the two crystallizable repeating units meet strict molecular requirements, the copolymers can crystallize in the same crystal lattice, in the entire composition range. In other words, the two comonomeric units along the chain can co-crystallize regardless of the composition. Therefore, the two comonomers can be considered miscible in the crystalline state. This case is referred to as total inclusion of comonomers in a single crystal lattice or isomorphic behavior, and as far as we are aware, it has never been obtained for aliphatic polyethers.

\section{Expanding the scope of the polymerization to terpolymers}

In order to expand the scope of the polymerization, a random terpolymer was also synthetized by the polymerization of 1,6-hexanediol, 1,10-decanediol and 1,12-dodecanediol using the same synthetic methodology (Figure 7a, entry 16). Herein, due to the complete overlapping of the $\mathrm{H}$ signals corresponding to 1,6-hexanediol, 1,10-decanediol and 1,12dodecanediol repetitive units (Figures $7 \mathrm{~b}$ and c) the molar composition of the terpolymer was 
calculated from the ${ }^{13} \mathrm{C}$ NMR spectrum and the result was C6/C10/C12 (27/46/27) (SI). The molecular weight was determined by SEC. The SEC trace showed a monomodal distribution suggesting the presence of the 3 comonomers in the polymer chain (Figure S9).

(a)

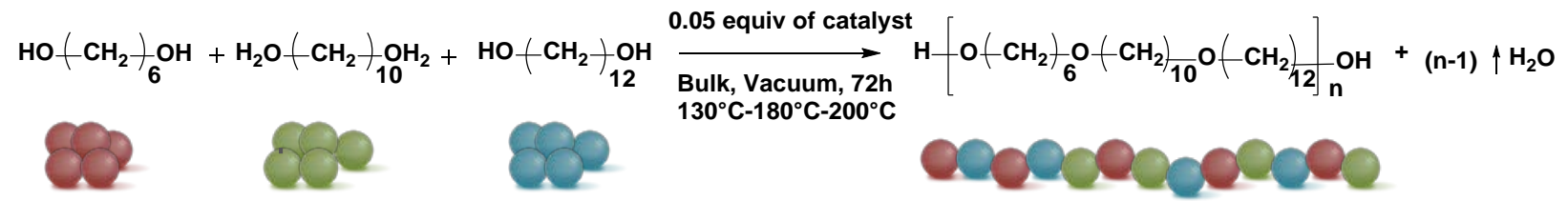

(b)

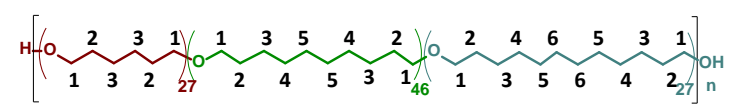

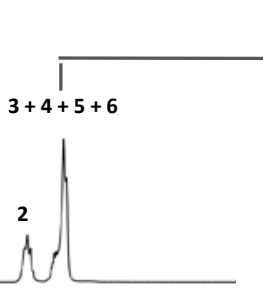

$\begin{array}{lllllllllllll}5.0 & 4.6 & 4.2 & 3.8 & 3.4 & 3.0 & 2.6 & 2.2 & 1.8 & 1.4 & 1.0 & 0.6 & 0.2 \\ \mathrm{ppm}\end{array}$ (c)

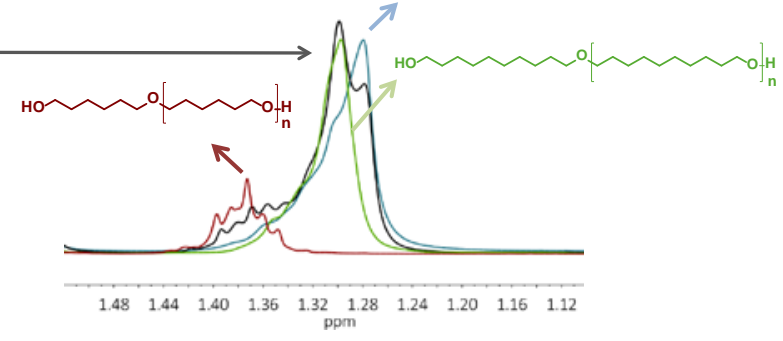

Figure 7. a) Synthesis route of random terpolymer using MSA:TBD (3:1) as catalyst, b) ${ }^{1} \mathrm{H}$ NMR spectrum of the terpolymer C6/C10/C12 and c) region of the ${ }^{1} \mathrm{H}$ NMR spectra of the terpolymer in comparison to the homopolymers. 
Table 4. Molecular characteristics of the terpolymer together with the thermal properties.

\begin{tabular}{llllllllll}
\hline Entry & $\begin{array}{l}\text { (C6/C10/C12) } \\
\% \text { in the feed }\end{array}$ & $\begin{array}{l}(\mathrm{C} 6 / \mathrm{C} 10 / \mathrm{C} 12) \\
\% \begin{array}{c}\text { in the } \\
\text { polymer }\end{array}\end{array}$ & $\begin{array}{l}\mathrm{Mn}^{\mathrm{a}} \\
(\mathrm{g} / \mathrm{mol})\end{array}$ & $\begin{array}{l}\mathrm{Mn}^{\mathrm{b}} \\
(\mathrm{g} / \mathrm{mol})\end{array}$ & $\mathrm{Ð}$ & $\begin{array}{l}T_{c} \\
\left({ }^{\circ} \mathrm{C}\right)\end{array}$ & $\begin{array}{l}\Delta H_{c} \\
(\mathrm{~J} / \mathrm{g})\end{array}$ & $\begin{array}{l}T_{m} \\
\left({ }^{\circ} \mathrm{C}\right)\end{array}$ & $\begin{array}{l}\Delta H_{m} \\
(\mathrm{~J} / \mathrm{g})\end{array}$ \\
\hline 1 & $100 / 0 / 0$ & - & 10000 & 19000 & 2.0 & 35.0 & -75 & 54.9 & 83 \\
\hline 14 & $0 / 0 / 100$ & - & 3200 & 5200 & 2.2 & 68.4 & -157 & 84.7 & 166 \\
\hline 15 & $0 / 100 / 0$ & - & 6800 & 8200 & 2.1 & 63.0 & -135 & 80.4 & 142 \\
\hline 16 & $33 / 33 / 33$ & $27 / 46 / 27$ & 4100 & 6900 & 2.0 & 56.0 & -173 & 75.1 & 179
\end{tabular}

${ }^{\mathrm{a}}$ Determined by ${ }^{1} \mathrm{H}$ NMR spectroscopy in $\mathrm{CDCl}_{3},{ }^{\mathrm{b}}$ Determined by $\mathrm{SEC}$ in $\mathrm{CHCl}_{3},{ }^{\mathrm{c}}$ Determined
by ${ }^{13} \mathrm{C}$ NMR spectroscopy in $\mathrm{CDCl}_{3}$

In addition to the comprehensive thermal characterization carried out to the copolyethers, the non-isothermal crystallization behavior of the random terpolymer was investigated by DSC and compared to the three poly(oxyhexamethylene), poly(oxydecamethylene) and poly(oxydodecamethylene) homopolyethers. The heating and cooling scans of the materials are represented in Figure 8 and S10 respectively. As observed in the copolymers, the terpolymer also shows a single melting and crystallization peak with $T_{m}$ and $T_{c}$ values for the terpolymer in between the values given by the homopolymers. Further analysis will be needed to ascertain if this terpolymer is also crystallizing in a single unit cell, as well as exploring the effects of composition. However, that is outside the scope of the present work and we just wanted to show the potentiality of the synthetic path to prepare novel terpolyethers. 


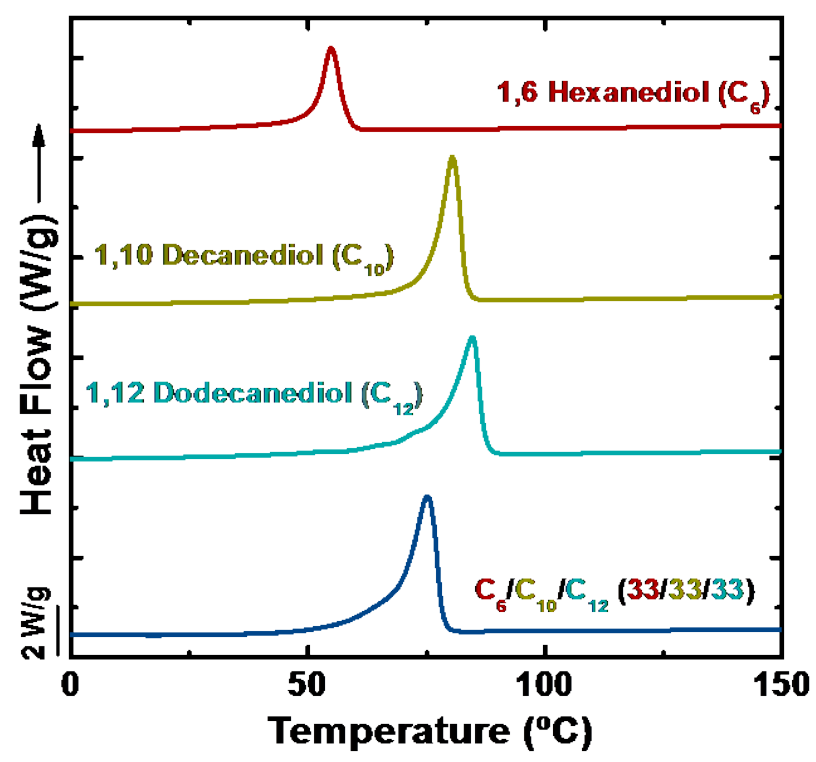

Figure 8. DSC heating scans for the indicated polyethers and terpolyether.

\section{CONCLUSIONS}

A series of aliphatic poly(oxyhexamethylene-ran-dodecamethylene)s random copolyethers were successfully synthesized by self-condensation of two different diols differing in chain length: 1,6hexanediol and 1,12-dodecanediol. The seven copolymers prepared with different compositions were completely random according to NMR and their number average molecular weights varied between 5900 and $17400 \mathrm{~g} \mathrm{~mol}^{-1}$. According to DSC and WAXS, these random copolyethers exhibit the following general behavior: (a) they crystallize in the entire composition range despite being random, (b) their melting points varied with composition according to a simple rule of mixtures, (c) WAXS results show that they crystallize in a single unit cell whose dimensions exhibit a weak but linear variation with copolymer composition. Thus, we can conclude that the copolyethers prepared here are isomorphic. Finally, a random terpolyether was also synthesized with the same route employed to obtain the copolyethers and a material with a single melting point 
was obtained. Therefore, this synthetic route can be tailored to prepare long chain aliphatic copolyethers and terpolyethers with a given melting temperature for specific applications.

\section{ASSOCIATED CONTENT}

Additional experimental details including ${ }^{1} \mathrm{H}$ and ${ }^{13} \mathrm{C}$ NMR spectra and DSC.

\section{AUTHOR INFORMATION}

\section{Corresponding Authors}

*Alejandro J. Müller and Haritz Sardon. E-mails: haritz.sardon@ehu.es, alejandrojesus.muller@ehu.es

\section{Present Addresses}

†If an author's address is different than the one given in the affiliation line, this information may be included here.

\section{Author Contributions}

The manuscript was written by contributions of all authors. All authors have given approval to the final version of the manuscript. $¥$ These authors contributed equally. (match statement to author names with a symbol)

\section{Funding Sources}

Any funds used to support the research of the manuscript should be placed here (per journal style).

\section{Notes}


Any additional relevant notes should be placed here.

\section{ACKNOWLEDGMENTS}

The authors thank the European Commission for its financial support through the projects SUSPOL-EJD 642671. Haritz Sardon and David Mecerreyes gratefully acknowledge financial support from MINECO through project POLYCE. A. J. Müller, O. Coulembier and H. Sardon also acknowledge European funding by the RISE BIODEST project (H2020-MSCA-RISE-2017778092). The authors also thank the technical and human support provided by Mrs. Sofia Guezala (SGIker) of UPV/EHU for the NMR analysis. H. Sardon, A.J. Müller and I. Flores acknowledge funding and beam time from ALBA Synchrotron facility through the project: 2017092338 (2018). A. J. Müller gratefully acknowledges financial support from MINECO through project MAT201783014-C2-1-P. A. Etxeberria acknowledges financial support from the Basque Government (GIC

IT-618-13). O. C. is Research Associate for the F.R.S.-FNRS. Irma Flores would like to acknowledge Conacyt (Mexico) for supporting her PhD studies with a scholarship.

\section{ABBREVIATIONS}

MSA, methanesulfonic acid, TBD, 1,5,7-triazabicyclo[4.4.0]dec-5-ene, NEMO, Non-Eutectic Mixture Organocatalyst.

\section{REFERENCES}

(1) Klein, R.; Wurm, F. R. Aliphatic Polyethers: Classical Polymers for the 21st Century. Macromol. Rapid Commun. 2015, 36 (12), 1147-1165. DOI:10.1002/marc.201500013.

(2) Meabe, L.; Lago, N.; Rubatat, L.; Li, C.; Müller, A. J.; Sardon, H.; Armand, M.; Mecerreyes, D. Polycondensation as a Versatile Synthetic Route to Aliphatic Polycarbonates for 
Solid Polymer Electrolytes. Electrochimica Acta 2017, 237, 259-266. DOI:10.1016/j.electacta.2017.03.217.

(3) Knop, K.; Hoogenboom, R.; Fischer, D.; Schubert, U. S. Poly(ethylene Glycol) in Drug Delivery: Pros and Cons as Well as Potential Alternatives. Angew. Chem. Int. Ed Engl. 2010, 49 (36), 6288-6308. DOI:10.1002/anie.200902672.

(4) Engels, H.-W.; Pirkl, H.-G.; Albers, R.; Albach, R. W.; Krause, J.; Hoffmann, A.; Casselmann, H.; Dormish, J. Polyurethanes: Versatile Materials and Sustainable Problem Solvers for Today's Challenges. Angew. Chem. Int. Ed. 2013, 52 (36), 9422-9441. DOI:10.1002/anie.201302766.

(5) Perry, S.; Hibbert, H. Studies on Reactions Relating to Carbohydrates and Polysaccharides. LXI. The Mechanism of Polymerization of Ethylene Oxide ${ }^{1}$. J. Am. Chem. Soc. 1940, 62 (10), 2599-2604. DOI:10.1021/ja01867a005.

(6) Vandenberg, E. J. Organometallic Catalysts for Polymerizing Monosubstituted Epoxides. J. Polym. Sci. 1960, 47 (149), 486-489. DOI:10.1002/pol.1960.1204714947.

(7) Dreyfuss, M. P.; Dreyfuss, P. A “living” Polymer after Cationic Initiation. Polymer 1965, 6 (2), 93-95. DOI:10.1016/0032-3861(65)90018-2.

(8) Uhrich, K. E.; Hawker, C. J.; Frechet, J. M. J.; Turner, S. R. One-Pot Synthesis of Hyperbranched Polyethers. Macromolecules 1992, 25 (18), 4583-4587. DOI:10.1021/ma00044a019.

(9) Rhoad, M. J.; Flory, P. J. The Synthesis of Polymeric Ethers. J. Am. Chem. Soc. 1950, 72 (5), 2216-2219. DOI:10.1021/ja01161a096. 
(10) Kobayashi, S.; Tadokoro, H.; Chatani, Y. Structural Studies on Polyethers, [-(CH2)m-O]n. VI. The Higher Members with $\mathrm{M}=$ 6-10, 12. Makromol. Chem. 1968, 112 (1), 225-241. DOI:10.1002/macp.1968.021120120.

(11) Zhang, S.; Féret, A.; Lefebvre, H.; Tessier, M.; Fradet, A. Poly(oxyalkylene) Synthesis in Brønsted Acid Ionic Liquids. Chem. Commun. 2011, 47 (39), 11092-11094. DOI:10.1039/C1CC14162G.

(12) Dannecker, P.-K.; Biermann, U.; von Czapiewski, M.; Metzger, J. O.; Meier, M. A. R. Renewable Polyethers via GaBr3-Catalyzed Reduction of Polyesters. Angew. Chem. Int. Ed. 2018, 57 (28), 8775-8779. DOI:10.1002/anie.201804368.

(13) Basterretxea, A.; Gabirondo, E.; Jehanno, C.; Zhu, H.; Flores, I.; Müller, A. J.; Etxeberria, A.; Mecerreyes, D.; Coulembier, O.; Sardon, H. Polyether Synthesis by Bulk Self-Condensation of Diols Catalyzed by Non-Eutectic Acid-Base Organocatalysts. ACS Sustain. Chem. Eng. 2019, 7 (4), 4103-4111. DOI:10.1021/acssuschemeng.8b05609.

(14) Pérez-Camargo, R. A.; Arandia, I.; Safari, M.; Cavallo, D.; Lotti, N.; Soccio, M.; Müller, A. J. Crystallization of Isodimorphic Aliphatic Random Copolyesters: Pseudo-Eutectic Behavior and Double-Crystalline Materials. Eur. Polym. J. 2018, 101, 233-247. DOI:10.1016/j.eurpolymj.2018.02.037.

(15) Allegra, G.; Bassi, I. W. Isomorphism in Synthetic Macromolecular Systems. In Fortschritte der Hochpolymeren-Forschung; Advances in Polymer Science; Springer Berlin Heidelberg, 1969; pp 549-574. 
(16) Liang, Z.; Pan, P.; Zhu, B.; Inoue, Y. Isomorphic Crystallization of Aliphatic Copolyesters Derived from 1,6-Hexanediol: Effect of the Chemical Structure of Comonomer Units on the Extent of Cocrystallization. Polymer 2011, 52 (12), 2667-2676. DOI:10.1016/j.polymer.2011.04.032.

(17) Natta, G.; Corradini, P.; Sianesi, D.; Morero, D. Isomorphism Phenomena in Macromolecules. J. Polym. Sci. 1961, 51 (156), 527-539. DOI:10.1002/pol.1961.1205115610.

(18) Ye, H.-M.; Wang, R.-D.; Liu, J.; Xu, J.; Guo, B.-H. Isomorphism in Poly(butylene Succinate-Co-Butylene Fumarate) and Its Application as Polymeric Nucleating Agent for Poly(butylene Succinate). Macromolecules 2012, 45 (14), 5667-5675. DOI:10.1021/ma300685f.

(19) Yu, Y.; Sang, L.; Wei, Z.; Leng, X.; Li, Y. Unique Isodimorphism and Isomorphism Behaviors of Even-Odd Poly(hexamethylene Dicarboxylate) Aliphatic Copolyesters. Polymer 2017, 115, 106-117. DOI:10.1016/j.polymer.2017.03.034.

(20) Bossion, A.; Heifferon, K. V.; Meabe, L.; Zivic, N.; Taton, D.; Hedrick, J. L.; Long, T. E.; Sardon, H. Opportunities for Organocatalysis in Polymer Synthesis via Step-Growth Methods. Prog. Polym. Sci. 2019, 90, 164-210. DOI:10.1016/j.progpolymsci.2018.11.003.

(21) Ceccorulli, G.; Scandola, M.; Kumar, A.; Kalra, B.; Gross, R. A. Cocrystallization of Random Copolymers of $\omega$-Pentadecalactone and $\varepsilon$-Caprolactone Synthesized by Lipase Catalysis. Biomacromolecules 2005, 6 (2), 902-907. DOI:10.1021/bm0493279.

(22) Latere Dwan’Isa, J.-P.; Lecomte, P.; Dubois, P.; Jérôme, R. Synthesis and Characterization of Random Copolyesters of $\varepsilon$-Caprolactone and 2-Oxepane-1,5-Dione. Macromolecules 2003, 36 (8), 2609-2615. DOI:10.1021/ma025973t. 
(23) Wunderlich, B. CHAPTER III - The Crystal Morphology. In Macromolecular Physics; Wunderlich, B., Ed.; Academic Press, 1973; pp 178-379. DOI:10.1016/B978-0-12-7656014.50008-1.

(24) Kdobayashhi, S.; Tadokoro, H.; Chatani, Y. Structural Studies on Polyethers, [-(CH2)mO-]N VI. The Higher Members with $\mathrm{M}=6-10,12$. Makromol. Chem. 1968, 112, 225-241. DOI:10.1002/macp.1968.021120120.

(25) Physical Properties of Polymers Handbook, 2nd ed.; Mark, J. E., Ed.; Springer: New York, 2006. 